\title{
The impact of medical student research as a discussion topic during the residency interview process
}

Kelly Daus and Matthew McEchron*

\begin{abstract}
Background: Students with a greater number of research experiences are more successful in the National Residency Match Program (NRMP.) As a result, approximately two-thirds of allopathic medical schools have implemented a scholarly research project (SP) as a part of their curriculum. While inclusion of an SP in the medical school curriculum increases research productivity, literature to date has not investigated the frequency with which it is a discussion topic during residency interviews.

Methods: One hundred twenty-three students from the graduating class of 2019 and 2020 at the University of Arizona College of Medicine - Phoenix (UACOMP) completed a 17-question survey examining the student's SP and whether they completed additional research, with an overall response rate of $82.6 \%$. Survey participants were asked to quantify how many residency interviewers asked about their SP or additional research during the interview process.

Results: Twenty-seven percent of interviewers asked students about their SP and $41 \%$ of interviewers asked students about additional non-SP research. 40\% of interviewers asked about research overall to include SP and/or non-SP research. A greater percentage of interviewers (50\%) asked students about their SP if they had undertaken additional research compared to interviewers of students who did not undertake additional research $(29 \%, p=0.0237)$. A greater percentage of interviewers at academic institutions (31\%) asked students about their SP, compared with a smaller percentage of interviewers at predominantly non-academic programs $(22 \%, p=0.0054)$. There were no significant differences in the proportion of interviewers asking about the SP based on the type of specialty, competitiveness of specialty, relatedness project topic to specialty, and publication/presentation status of project.
\end{abstract}

Conclusion: Student research experiences may serve as a frequent discussion topic during the residency interview. Approximately one-quarter of interviewers ask about the SP regardless of specialty, research topic, and publication/ presentation status of the project. Students with additional research experiences beyond their SP may experience a higher percentage of interviewers asking about their SP. Also, students applying to predominantly academic programs may experience a higher proportion of interview questions about research compared to peers interviewing at non-academic programs.

Keywords: Medical education, Scholarly research, Residency interview, Residency match

*Correspondence: mcechron@arizona.edu

University of Arizona College of Medicine - Phoenix, $475 \mathrm{~N}$ 5th St, Phoenix, AZ 85004, USA

\section{Background}

Throughout the current body of medical education literature various models of incorporating scholarly research within the undergraduate medical education curriculum have been described as well as their impact on student 
success [1-6]. Previous research has shown that osteopathic and allopathic medical students matching into residency programs have a significantly greater number of research accomplishments than unmatched applicants [7]. Although causation cannot be concluded from several studies in this area, there is clearly an association between research experience and increased match success [8, 9]. In the 2020 Match, U.S. M.D. seniors reported an average of 3.6 research experiences [10]. For almost all specialties, matched U.S. MD seniors had on average greater numbers of research experiences, research conference presentations, and publications compared to students who did not successfully match [10]. For specialties including dermatology, interventional radiology, neurosurgery, otolaryngology, orthopedic surgery, and radiation oncology, where the large number of applicants relative to the number of positions available is more pronounced, the number of research experiences undertaken is even greater [10]. Even prior to the match, authorship of one or more publications is associated with a greater number of interview invitations for integrated plastic surgery applicants [11] and over $90 \%$ of general surgery program directors state that they consider basic and clinical research almost always or all the time when evaluating candidates [12].

As medical students with a higher number of research experiences are more successful in the Match, almost two-thirds of allopathic medical schools have implemented a scholarly research project as a component of their curriculum with approximately one-third of schools making completion of this scholarly research project mandatory for graduation [13]. The University of Pittsburg School of Medicine assessed the research productivity of its students before and after the implementation of a mandatory scholarly project (SP) and while noting only a modest rise in the number of students engaged in research, they identified a significant increase in the number of students with publications and first authorship [14]. Research experience, publications, and conference presentations clearly impact an applicant's success in the Match, and this may motivate medical schools to make more research opportunities available for students.

Some objectives of mandatory scholarly research projects are to produce critical thinking life-long learners with self-directed independent learning skills, writing skills, and an understanding of the scientific method [13]. These key objectives of SP curricula are also highly desired characteristics in residency applicants [15]. The NRMP data suggest that research experience is an important component of the residency application [10]. This study sought to determine the frequency at which interviewers asked applicants about their SP during the residency interview process. We hypothesized that regardless of the research topic or publication outcome, a student's scholarly research project would be a frequent discussion topic during the interview.

\section{Methods}

The University of Arizona College of Medicine-Phoenix (UACOMP) requires students to complete a mandatory 4-year, longitudinal SP that is hypothesis driven and culminates in a poster presentation and written thesis. The present study surveyed fourth year medical students from the graduating class of 2019 and 2020 at UACOMP using an online survey approximately 2 months following completion of residency interviews and 2 weeks prior to the Match. Students were allotted 20 min during an inperson session on campus to complete the 17-question survey. This survey study was approved by the Institutional Review Board at the University of Arizona. Survey completion was optional, anonymous, and all participants agreed electronically to an informed consent prior to beginning the survey and could exit the survey at any time.

The survey examined the student's SP, volunteer experiences, work experiences, and non-SP research. The survey also determined if students published or presented research at a national conference, and whether the research topics related to the specialty sought by the medical student. Students were asked to estimate the number of interviewers they met with during the interview process and the number of interviewers who asked them about their SP, volunteer experiences, work experiences, and non-SP research. The survey also gathered baseline characteristics of students including specialty and predominant type of program the student interviewed with - academic or community. A full list of survey questions can be found in Fig. 1.

\section{Statistical analysis}

Survey results were collapsed across both classes to form a total survey population of 123 participants as there were no significant differences between the classes. Publication, presentation at a national conference, and topic relatedness of research to chosen specialty for both SP and non-SP research were reported as frequencies with percentages. The proportion of interviewers asking about SP, volunteer experiences, work experiences and non-SP research was calculated for each survey participant. These were then treated as a continuous variable and reported as means with standard deviations. Twoproportion z-tests with a significance level of 0.05 was used to determine whether the hypothesized difference between proportions of interviewers asking about SP differed significantly based on specialty type, competitiveness of specialty, publication of SP, presentation of SP, 


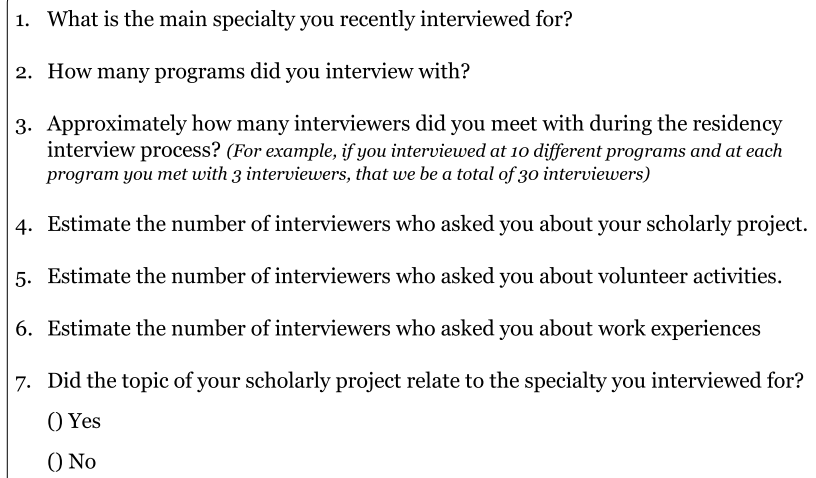

8. Has your scholarly project been published or do you anticipate it being published in the near future?

() Yes

() No

9. Have you presented your scholarly project at a national conference or do you anticipate presenting it at a national conference?

() Yes

() No

10. During medical school did you engage in research projects outside of your scholarly project?

() Yes

() No

11. How many additional research projects did you engage in outside of your scholarly project?

12. Did the topic of your non-scholarly project research relate to the specialty you interviewed for?

() Yes

() No

() Some projects did and some did not

13. Has your non-scholarly project research been published or do you anticipate it being published in the near future?

() Yes

() No

14. Have you presented your non-scholarly project research at a national conference or do you anticipate presenting it at a national conference?

() Yes

() No

15. Estimate the number of interviewers who asked you about your non-scholarly project research.

16. Did you predominantly apply to and interview at residency programs with an Academic or a Clinical focus?

() All Academic

() Most were Academic

() $50 \%$ Academic, $50 \%$ Clinical

() Most were Clinical

() All Clinical

17. In the context of the residency interview process do you feel it was helpful to have a scholarly project requirement as a component of your medical school curriculum?

\section{() Strongly agree}

() Agree

() Neutral

() Disagree

() Strongly disagree

Fig. 1 Study Survey topic of SP, undertaking of additional non-SP research, and application to predominantly academic programs.

\section{Results \\ Baseline characteristics}

A total of 123 students participated in the survey from the graduating class of 2019 and 2020 at the UACOMP. A high percentage of the students completed the survey, with 62 out of the 67 students in the class of 2019 (92.5\%) and 61 out of the 82 students in the class of 2020 (74.3\%). The overall survey response rate was $82.6 \%$. The baseline characteristics for the survey participants from the Class of 2019 and 2020 can be found in Table 1. There were no significant differences in baseline characteristics with roughly two-fifths of the survey population interviewing for primary care $(40.7 \%)$ and three-fifths in non-primary care specialties (59.3\%). Approximately one-fifth of the survey participants (18.7\%) interviewed in more competitive specialties designated by having an annual number of applicants per position greater than 1.35 [10].

All students completed the mandatory SP curriculum, and their project title was included in their Medical Student Performance Evaluation (MSPE) letter as part of their residency application. The research characteristics of students' SP and non-SP research including publication status, presentation at a national conference, and topic relatedness to chosen specialty can be found in Table 2. Almost half of students reported publishing their SP (48\%), and one-third presented their SP at a national conference. The survey showed that $65 \%$ of students reported undertaking additional research not related to their mandatory SP. Over three-fourths of these students published their additional research in peer-reviewed journals (78\%) and approximately half (48\%) presented this additional research at a national conference.

\section{SP impact on the interview conversation}

The survey revealed that on average $40 \%$ of interviewers (SD 30.7) asked students about their research experiences, while $41 \%$ of interviewers (SD 42.7) asked students about volunteering experiences, and 35\% of interviewers (SD 32.9) asked students about work experiences as shown in Table 3. Specifically, with regard to the type of research discussed, an average of $27 \%$ (SD 27.0) and $41 \%$ (SD 32.0) of interviewers asked about the student's SP and additional research, respectively.

Survey data was analyzed to determine if the proportion of interviewers asking about a student's SP differed based on seven factors shown in Table 4. There were no significant differences between the proportion of interviewers asking about a student's SP based on the type of specialty or competitiveness of the specialty. Additionally, there were no significant differences between the 
Table 1 Baseline Characteristics

\begin{tabular}{|c|c|c|c|}
\hline & Class of 2019 & Class of 2020 & Total \\
\hline Number of Students & 62 & 61 & 123 \\
\hline Primary Care & 30 & 20 & $50(41 \%)$ \\
\hline Family Medicine & 7 & 7 & 14 \\
\hline Internal Medicine & 14 & 6 & 20 \\
\hline Internal Medicine-Pediatrics & 1 & 0 & 1 \\
\hline Pediatrics & 8 & 7 & 15 \\
\hline Non-Primary Care & 32 & 41 & $73(59 \%)$ \\
\hline Anesthesiology & 7 & 2 & 9 \\
\hline Child Neurology & 0 & 1 & 1 \\
\hline Diagnostic Radiology & 5 & 4 & 9 \\
\hline Emergency Medicine & 7 & 12 & 19 \\
\hline General Surgery & 1 & 3 & 4 \\
\hline Neurology & 1 & 1 & 2 \\
\hline Neurosurgery ${ }^{a}$ & 2 & 0 & 2 \\
\hline OB/GYN & 3 & 2 & 5 \\
\hline Ophthalmology ${ }^{a}$ & 0 & 2 & 2 \\
\hline Orthopedic Surgery ${ }^{a}$ & 1 & 5 & 6 \\
\hline Otolaryngology a & 2 & 3 & 5 \\
\hline Pathology & 1 & 0 & 1 \\
\hline Plastic Surgery ${ }^{a}$ & 0 & 2 & 2 \\
\hline Psychiatry & 1 & 3 & 4 \\
\hline Urology $^{a}$ & 1 & 1 & 2 \\
\hline
\end{tabular}

${ }^{a}$ more competitive specialties denoted by annual number of applicants per position $>1.35$

Table 2 Research Characteristics

\begin{tabular}{ll}
\hline & $\begin{array}{l}\text { Total Number } \\
\text { of Students } \\
\text { (\%) }\end{array}$ \\
\hline $\begin{array}{ll}\text { Scholarly Project } \\
\text { Published }\end{array}$ & $123(100 \%)$ \\
Presented at National Conference & $59(48 \%)$ \\
Topic Related to Chosen Specialty & $41(33 \%)$ \\
Additional Research & $58(47 \%)$ \\
Published & $80(65 \%)$ \\
Presented at National Conference & $62(78 \%)$ \\
Topic Related to Chosen Specialty & $39(49 \%)$ \\
\hline
\end{tabular}

proportion of interviewers asking about a student's SP based on the publication or presentation status of the project or whether the topic was related to the student's chosen specialty. However, the amount of research experience undertaken by the student outside of the SP had a significant impact on the proportion of interviewers asking about the SP. Results showed that $50 \%$ of interviewers (SD 26.2) asked students about their SP if they had undertaken additional research outside of their SP
Table 3 Mean Reported Proportion of Interviewers Asking about Research, Volunteering \& Work Experience

\begin{tabular}{ll}
\hline & $\begin{array}{l}\text { Proportion of } \\
\text { Interviewers (\%, } \\
\text { SD) }\end{array}$ \\
\hline Research Overall & $40 \%(30.7)$ \\
$\quad$ Scholarly Project & $27 \%(27.0)$ \\
Additional Research & $40 \%(32.0)$ \\
Volunteering & $41 \%(42.7)$ \\
Work Experiences & $35 \%(32.9)$ \\
\hline
\end{tabular}

compared to $29 \%$ of interviewers (SD 28.4) of students who did not undertake additional research $(p=0.0237)$. Furthermore, the predominant type of programs the student interviewed with (i.e., programs with an academic versus community focus) had a significant impact on the proportion of interviewers who asked about the SP. Students applying to "almost all" or "more than half" of programs with an academic or research focus had a greater proportion of interviewers (31\%, SD 27.9) asking them about their SP versus interviewers of students (22\%, SD 25.5) who reported applying to "none at all" or "less than half" of programs with an academic research focus $(p=0.0054)$.

Overall, $67 \%$ of students strongly agreed or agreed that it was helpful to have a scholarly project requirement as a component of their medical school curriculum. 19\% of students neither agreed nor disagreed with this statement and only $14 \%$ stated that they disagreed.

\section{Discussion}

This study provides unique insight into the impact of research experiences on the residency interview by showing that on average $40 \%$ of interviewers asked students about their research experiences. This supports the previously demonstrated observation in the literature that students with a greater number of research experiences are more likely to be successful in the NRMP match [7-10]. These findings also challenge applicants to view these experiences as more than simply a bullet on their resume but rather as a dynamic piece of their application about which they should anticipate questions during the interview process. Although this study suggests that interviewers inquire about research experiences less than half of the time, this knowledge provides value to students and advisors as they seek to better understand the role of research on the residency application. Research experiences are discussed during the residency interview at a similar frequency compared with volunteer experiences and work experiences. 
Table 4 Factors Impacting Mean Reported Proportion of Interviewers Asking about the Scholarly Project

\begin{tabular}{|c|c|c|}
\hline & Proportion of Interviewers Asking about SP (\%, SD) & $p$-value \\
\hline Type of Specialty & & 0.2221 \\
\hline Primary Care & $33 \%(28.1)$ & \\
\hline Non-Primary Care & $23 \%(25.6)$ & \\
\hline Competitiveness of Specialty & & 0.2856 \\
\hline More Competitive & $18 \%(26.3)$ & \\
\hline Less Competitive & $29 \%(29.9)$ & \\
\hline Publication Status & & 0.9005 \\
\hline Published & $27 \%(27.0)$ & \\
\hline Not Published & $26 \%(27.1)$ & \\
\hline Presentation Status & & 0.1876 \\
\hline Presented & $34 \%(30.4)$ & \\
\hline Not Presented & $23 \%(24.1)$ & \\
\hline Topic Relatedness to Specialty & & 0.4553 \\
\hline Topic Related & $30 \%(27.2)$ & \\
\hline Topic Unrelated & $24 \%(26.7)$ & \\
\hline Amount of Research Undertaken & & 0.0237 \\
\hline Additional Research & $50 \%(26.2)$ & \\
\hline Only Scholarly Project & $29 \%(28.4)$ & \\
\hline Type of Residency Programs & & 0.0054 \\
\hline Almost All - More than Half Academic Programs & $31 \%(27.9)$ & \\
\hline None - Less than half Academic Programs & $22 \%(25.5)$ & \\
\hline
\end{tabular}

All medical students at UACOMP are required to complete a longitudinal SP. Among the medical students surveyed in this study, approximately one-quarter (27\%) of their interviewers utilized this as a discussion topic during their residency interview. This finding may encourage medical schools to consider adding programmatic objectives focused on student communication about their scholarly research. This may create opportunities for teaching students not only how to be investigators, but how to communicate their scholarly research in a compelling way. Additionally, a student's chosen specialty, competitiveness of specialty and relatedness of SP topic to their chosen specialty had no significant impact on the proportion of interviewers inquiring about their SP. This may indicate that interviewers are more interested in the types of skills and traits acquired through scholarly research than the actual topic of the research. Furthermore, this observation may serve to diminish the notion that research is not important for students applying to primary care specialties. Overall, a mandatory scholarly project during medical school could provide a topic of conversation during the interview process regardless of the specialty students are applying for and the relatedness of their research topic to this specialty.

The literature suggests that students with a greater number of publications and presentations are more likely to be successful in the match than their peers [7-10].
This may lead students to believe that research is only valuable on their application if these milestones are obtained, however, the findings of this study suggest that research may be important as a discussion topic during the interview regardless of whether it received publication and presentation status. It is likely that interviewers see value in discussing these academic endeavors with students regardless of the project's result. The impressive frequency of publication (48 and 78\%) and presentation (33 and 48\%) of students' SP and additional non-SP research, respectively, should not be overlooked. Despite publication and presentation status not significantly impacting the number of interview questions a student received about research, the incorporation of a formal SP curriculum does appear to lead to increased achievement of these milestones. Although measuring the impact of this is beyond the scope of this study, this observation is in line with prior conclusions drawn by the University of Pittsburg [11].

There are two circumstances in which students may anticipate a greater number of interview questions about their SP. First, if the residency setting is academic the percentage of interviewers asking about a student's SP increases from 33 to $50 \%$. It is understandable that interviewers at academic programs may use research endeavors to learn more about an applicant's attributes while interviewers at community programs may utilize 
alternative discussion topics to get to know the applicant. Second, students who undertake additional research beyond their mandated SP receive a greater number of interview questions about the topic compared to those students who do not undertake additional research, 50\% compared to $29 \%$, respectively. It is reasonable that with research experiences making up a more substantial piece of these student's extracurricular activities, the SP, as a piece of the research portfolio, becomes a more frequent part of the interview discussion than students who only completed mandatory research requirements.

\section{Limitations}

Although multiple interesting observations were revealed in our study, there are several limitations including a small sample size of residency applicants from only a single medical school. The retrospective nature of the survey lends itself to recall bias in which survey participants may not have been accurate in their estimations of the number of interviewers asking them about their experiences. There was range of one to 4 months between student completion of interviews and participation in the study survey. Furthermore, the study population is one-sided in that it only examines the experiences of the interviewee regarding discussions about research during the residency interview and does not evaluate the experience or intentions of the interviewer. Despite these limitations, this study provides unique quantitative observations about the topics of discussion during the residency interview. The findings of this study could help to guide future medical students within our institution regarding the impact of their scholarly project in the residency interview, and it is our hope that these findings may be useful for research programs at other schools of medicine as well.

\section{Conclusion}

Student research experiences may serve as a frequent discussion topic during the residency interview. Approximately one-quarter of interviewers (27\%) ask about the scholarly project regardless of type of specialty, competitiveness of specialty, relatedness of project topic to specialty, and publication/presentation status of project. Students with additional research experiences beyond their scholarly project may experience up to half of interviewers asking about their scholarly project whereas students applying to community programs with less academic/research focus may experience fewer questions about research compared to their peers applying to more academic programs. These findings have implications for medical students as they choose research projects and medical school administrators as they consider the impact of research on the success of their students in the residency match.

\section{Abbreviations}

NRMP: National Residency Match Program; SP: Scholarly project; UACOMP: University of Arizona College of Medicine - Phoenix; SD: Standard deviation; MSPE: Medical Student Performance Evaluation.

\section{Acknowledgements}

Thank you to Paul Kang for providing statistical advice, Cristal Cathey for IRB submission assistance and the entire Scholarly Project Team at the University of Arizona College of Medicine - Phoenix.

\section{Authors' contributions}

KD collected and analyzed data, and was a major contributor in writing manuscript, MM oversaw collection and analysis of data and contributed in writing manuscript. All authors read and approved the final manuscript.

Funding

Not applicable.

\section{Availability of data and materials}

The datasets used and/or analyzed during the current study are available from the corresponding author on reasonable request.

\section{Declarations}

\section{Ethics approval and consent to participate}

This study was approved by the University of Arizona Institutional Review Board. Additionally, the survey administered was approved by the Office of Assessment and Evaluation at the University of Arizona College of Medicine Phoenix. All study participants signed an electronic informed consent prior to completion of the study survey. All methods were carried out in accordance with relevant guidelines and regulations.

\section{Consent for publication}

Not applicable.

\section{Competing interests}

The authors declare that they have no competing interests.

Received: 8 March 2021 Accepted: 20 October 2021

Published online: 01 November 2021

\section{References}

1. Ebbert A. A retrospective evaluation of research in the medical curriculum. J Med Educ. 1960;35:637-43.

2. Jacobs CD, Cross PC. The value of medical student research: the experience at Stanford University School of Medicine. Med Educ. 1995;29(5):342-6.

3. Gotterer GS, O'Day D, Miller BM. The emphasis program: a scholarly concentrations program at Vanderbilt University School of Medicine. Acad Med. 2010;85(11):1717-24.

4. Schor NF, Troen P, Kanter SL, Levine AS. The scholarly project initiative: introducing scholarship in medicine through a longitudinal, mentored curricular program. Acad Med. 2005;80:824-31.

5. Boninger M, Troen P, Green E, et al. Implementation of a longitudinal mentored scholarly project: an approach at two medical schools. Acad Med. 2010;85:429-37.

6. Green EP, Borkan JM, Pross SH, et al. Encouraging scholarship: medical school programs to promote student inquiry beyond the traditional medical curriculum. Acad Med. 2010;85(3):409-18.

7. Matthews CN, Estrada DC, George-Weinstein M, Claeson KM, Roberts MB Evaluating the influence of research on match success for osteopathic and allopathic applicants to residency programs. J Am Osteopath Assoc. 2019;119(9):588-96. https://doi.org/10.7556/jaoa.2019.102. 
8. Agarwal P, Khalafallah AM, Hersh EH, Ivan ME, Mukherjee D. Impact of american association of neurological surgeons medical student interest groups on participation in organized neurosurgery, research productivity, and residency match success. World Neurosurg. 2020;138:e437-44. https://doi.org/10.1016/j.wneu.2020.02.153.

9. Rinard JR, Mahabir RC. Successfully matching into surgical specialties: an analysis of national resident matching program data. J Grad Med Educ. 2010;2(3):316-21. https://doi.org/10.4300/JGME-D-09-00020.1.

10. Characteristics of U.S. MD Seniors Who Matched to Their Preferred Specialty in the 2020 Main Residency Match. https://www.nrmp.org/mainresidency-match-data/. Accessed 01 Sept 2020

11. Rogers CR, Gutowski KA, Munoz-Del Rio A, et al. Integrated plastic surgery residency applicant survey: characteristics of successful applicants and feedback about the interview process. Plast Reconstr Surg. 2009;123(5):1607-17. https://doi.org/10.1097/PRS.0b013e3181a075ea.

12. Melendez MM, Xu X, Sexton TR, Shapiro MJ, Mohan EP. The importance of basic science and clinical research as a selection criterion for general surgery residency programs. J Surg Educ. 2008;65(2):151-4. https://doi. org/10.1016/j.jsurg.2007.08.009.
13. Kaur, P., Hartnett, E., Wypiszynski, S., \& McEchron, M. (December, 2020). Components of the Required Scholarly Project for U.S. Allopathic Medical Schools Poster presented at: Virtual, UA, USA: AMA Research Symposium; 2020.

14. Conroy MB, Shaffiey S, Jones S, et al. Scholarly research projects benefit medical students' research productivity and residency choice: outcomes from the university of Pittsburgh school of medicine. Acad Med. 2018. https://doi.org/10.1097/ACM.0000000000002328.

15. VanOrder T, Robbins W, Zemper E. Residency program directors' interview methods and satisfaction with resident selection across multiple specialties. J Am Osteopath Assoc. 2017;117(4):226-32. https://doi.org/10.7556/ jaoa.2017.040.

\section{Publisher's Note}

Springer Nature remains neutral with regard to jurisdictional claims in published maps and institutional affiliations.
Ready to submit your research? Choose BMC and benefit from:

- fast, convenient online submission

- thorough peer review by experienced researchers in your field

- rapid publication on acceptance

- support for research data, including large and complex data types

- gold Open Access which fosters wider collaboration and increased citations

- maximum visibility for your research: over $100 \mathrm{M}$ website views per year

At BMC, research is always in progress.

Learn more biomedcentral.com/submissions 